\title{
FOOD QUALITY MANAGEMENT BASED ON QUALIMETRIC METHODS
}

Valentina YANKOVSKAYA, Department of Commodity Quality Management and Merchandizing, Technological faculty, Russian State Agrarian University, academician of the Russian Academy of Natural Sciences - Moscow Agricultural Academy named after K.A. Timiryazev, Adress: 127550, Moscow, st.Timiryazevskaya,49; vs3110@yandex.ru

Nina DUNCHENKO, Department of Commodity Quality Management and Merchandizing, Technological faculty, Russian State Agrarian University, academician of the Russian Academy of natural Sciences - Moscow Agricultural Academy named after K.A. Timiryazev, Adress: 127550, Moscow, st. Timiryazevskaya, 49; dunchenko.nina@yandex.ru

Dinara ARTYKOVA, Postgraduate Department of Commodity Quality Management and Merchandizing, Technological faculty, Russian State Agrarian University, academician of the Russian Academy of natural Sciences - Moscow Agricultural Academy named after K.A. Timiryazev, Adress: 127550, Moscow, st. Timiryazevskaya, 49; dinara-art@bk.ru

Marina GINZBURG, Postgraduate Department of Commodity Ouality Management and Merchandizing, Technological faculty, Russian State Agrarian University, academician of the Russian Academy of natural Sciences - Moscow Agricultural Academy named after K.A. Timiryazev, Adress: 127550, Moscow, st. Timiryazevskaya, 49; marina-micra@yandex.ru

Kermen MIKHAYLOVA, Postgraduate Department of Commodity Quality Management and Merchandizing, Technological faculty, Russian State Agrarian University, academician of the Russian Academy of natural Sciences - Moscow Agricultural Academy named after K.A. Timiryazev, Adress: 127550, Moscow, st.Timiryazevskaya,49; mikhaylovekermen@mail.ru

Elena VOLOSHINA, Department of Commodity Quality Management and Merchandizing, Technological faculty, Russian State Agrarian University, academician of the Russian Academy of natural Sciences - Moscow Agricultural Academy named after K.A. Timiryazev, Adress: 127550 , Moscow, st. Timiryazevskaya, 49; yudakovaes@gmail.com (corresponding autor)

Fusing best international and local quality management and control practices is one of the most effective ways to gain competitive advantage. Among other things, this includes implementing "customer focus" and "factual decision-making", the key principles of Universal Quality Management, through qualimetric models. The authors have identified qualimtric models with the best quality management potential across the food processing industry, at different product life cycle stages. They especially emphasize the potential of applying qualimetric forecast to food quality and safety. The authors have identified the main stages of product quality metrics forecasting to predict and achieve the desirable food quality in the most effective way possible. The proposed methods are a combination of qualifying methods and world's best quality management tools and techniques. With the example of quality management in curd products at the development stage the authorship points out the indicators defining product quality and safety, ranks value in building product quality, gives a math formula to describe product quality and an algorithm to assess product quality based on a comprehensive quality indicator and deduce recommendations to achieve desirable and predictable product properties. The proposed stages of qualimetric forecasting, based on the integration of qualimetric models in quality management, have been tested on some curd products in production and proven to be practically effective.

Keywords: agricultural products, assessment, value indicators, competitiveness, estimation methods, food products, product development, prediction, property tree, qualimetric method, qualimetric model, qualimetry, quality, safety tree, quality management, quality of life.

\section{INTRODUCTION}

Needless to say, estimating various objects is a necessity for success in any human activity. This is especially true for quality management. Many fundamental documents in food quality management (such as ISO 9001:2015 and ISO 9004: 2009) and food safety (ISO 22000 series) have many provisions that see valuation as mandatory. Moreover, valuation results directly depend on the procedure, how properly it is organized, i.e. on whether scientifically based valuation methodology is used (Azgaldov et al, 2012, Yankovskaya, 2008). Qualimetry is a scientific discipline which regards developing qualimetric models (quantifying the quality of any material and intangible objects of the real world).

The field of qualimetry application in quality management is limitless in practical terms (Vasilev et al, 2011). The flexibility of qualimetric analysis methods makes them useful for evaluation of any objects at any stages of the life cycle: from product design estimate at the planning stage to after-sales estimate (Yankovskaya et al, 2012). Applying qualimetric forecasting, which involves a combination of any methods for in-depth analysis of factors that determine product quality, consumer expectations, feasibility of methods to improve products and forecasting the properties of products has a significant potential (Khvastunov et al, 2012). Unfortunately, contrary to all the advantages of qualimetry methods, sources only cite occasional use of qualimetry in management practice (Azgaldov, Kostin, 2012). It's worth mentioning that the use of qualimetry methods in management can reasonably be viewed as a way to intensify competition, because

Copyright (C) 2019 The Authors. Published by Vytautas Magnus University. This is an open-access article distributed under the terms of the Creative Commons Attribution License (CC BY 4.0), which permits unrestricted use, distribution, and reproduction in any medium, provided the original author and source are credited. 
qualimetry methods ensure obtaining more accurate data and thereby improve the value of decisions made, management quality, efficient use of enterprise resources and orderly use of material investments (Dunchenko, Yankovskaya, 2012, 2017). At the same time, using qualifying methods in quality management does not require considerable extra costs, changes in the corporate structure, or document alteration (Mikhailova K.V. et al, 2018).

To demonstrate application of a set of qualimetric methods for a number of quality management problems, we've developed a model for quantitative forecasting of product quality properties. As an object, we chose curd products, as market competition is high in this product category and it is important to improve non-price competition (Yankovskaya, 2007).

To do so, we analyzed the field of qualimetry application in management, identified stages of qualifying forecasting and carried a number of experimental sociological studies with the purpose to test the proposed qualimetric forecasting models in building new types of competitive curd products with desirable properties.

\section{RESEARCH METHODS}

Azgaldov's scientific work provides the framework to identify product qualimetric forecasting stages (Azgaldov et al, 2012; Khvastunov et al, 2009, 2012; Akao Y.; Mizuno, Akao, 1994; Cooper, 1995).

The proposed model involves a combination of qualimetric methods (property tree, comprehensive assessment method, qualimetric model, expert qualimetry) and other worldwide accepted quality management tools (Pareto chart, affinity diagram), technologies and methods (Quality Function Deployment, factorial experiment). The study also applied sociological, statistical, and standard experimental methods for viewing processed food properties.

\section{RESEARCH FINDINGS}

To establish the most effective qualimetry methods in management and select ones to further use in developing qualimetric forecast stages, we analyzed practical scientific findings in qualimetric methods for management. Figure 1 shows the most effective application of qualimetric methods within the life cycle of food products.

It should be noted that the most employed qualimetric control methods are present in product design (Yankovskaya, 2007) (especially, in project estimation, qualimetric forecasting, the value for money ratio of a designed product, etc.), as well as finished product estimation (Kuschev et al, 2009), involving expert qualimetry methods (Khvastunov et al, 2009). Furthermore, expert qualifiers improve the selection of experts for expert groups and enhance the quality of their expertise or decisions (Danchenko, Yankovskaya, 2016). Remarkably, the scope of qualimetric model application does is not limited to a company's marketing, production, and management. Qualimetric methods are also applicable across other structural units of the company, for example, to give an estimation to suppliers, working or recruitment conditions (Dunchenko, Yankovskaya, 2017). Using qualimetric forecasting to trace various properties of products, in production, for the most part, is an upcoming trend (Yankovskaya, 2008).

Besides, the international management practice tends to use several approaches and models based on key qualimetry principles, such as analysis of hierarchies, benchmarking (Azgaldov, Kostin, 2012), or incentive-driven criteria for quality management (Yankovskaya, 2008).

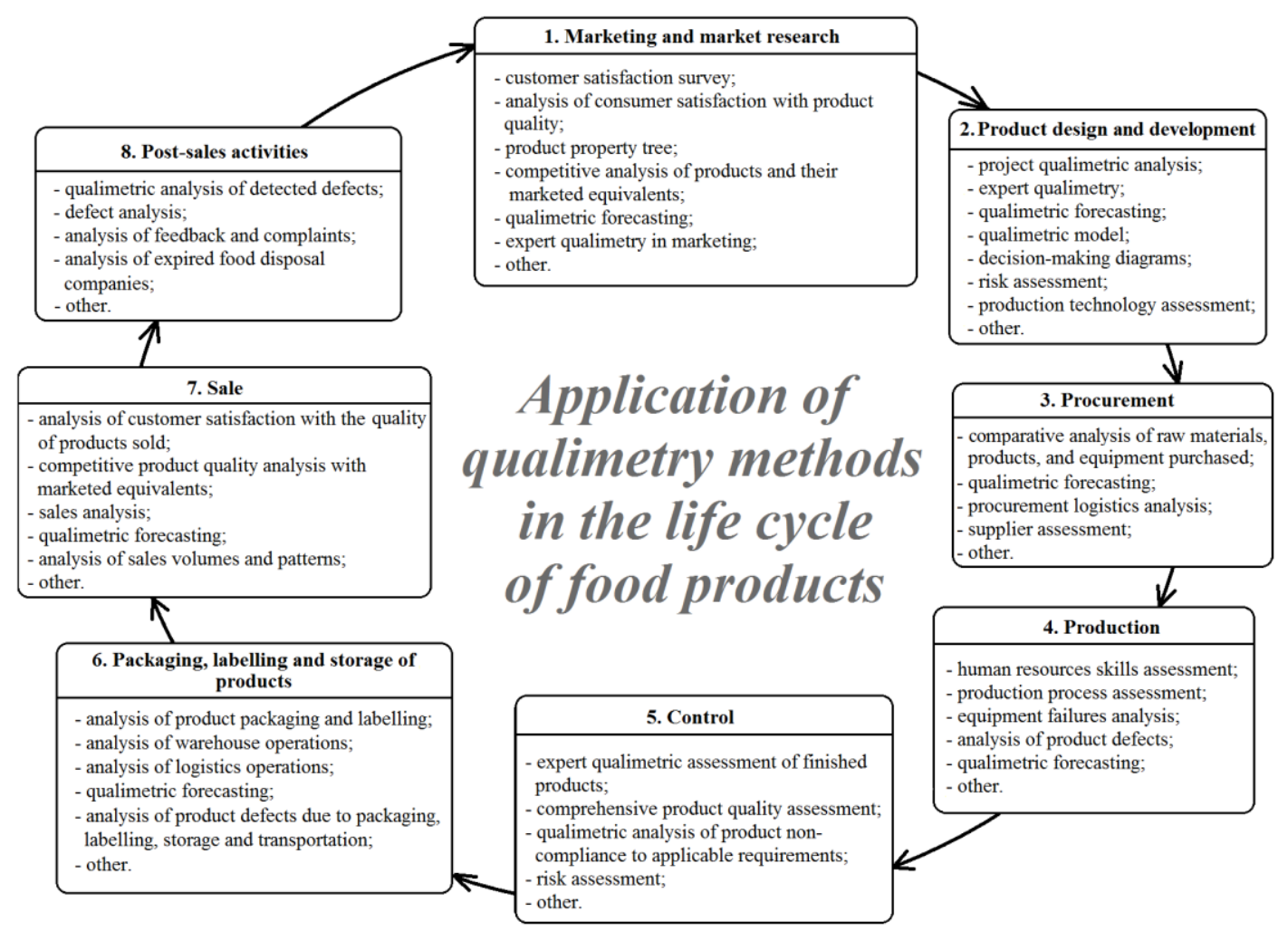

Figure 1 . Ways to apply qualimetry methods in the life cycle of food products 
Qualimetric product quality forecasting is paramount because it serves to solve management problems comprehensively, at multiple key stages of the product life cycle (Khvastunov, 2009, 2012).

The given basic steps of qualimetric product quality forecasting include quality and safety article identification, construction of a property tree and calculation of value factors for quality indicators, complex quantitative assessment methods, identification of numerical values for quality indicators that a food product should have to meet consumer expectations, development of techniques to forecast and control properties of the finished product.

Practically implemented, the proposed stages of qualimetric product quality forecasting involve development or adjustment of the existing production technology, establishment of recipes to achieve the desirable product quality. Using the proposed formula of qualitative assessment to run a comparative analysis of newer and competitors' products helps evaluate the validity of adopted technological solutions.

The conducted research (a 250-strong poll, property tree (Figure 2), value factoring of quality indicators, customer requirements matrix with target quality indicators for developed products, a comprehensive indicator formula for product quality (1) and (2) enables techniques to ensure desirable product quality.

The overall comprehensive indicator formula for qualimetric assessment of production, which meets mandatory safety $(a)$ and technological compliance $(b)$ requirements, is:

$$
K=a \cdot b \cdot \sum_{i=1}^{c} M_{i} \cdot k_{i}
$$

where $K$ is a comprehensive indicator formula for product quality; $a$ and $b$ are critical safety and technological compliance indicators $M_{i}$ is the value factor of the $i$-indicator of consumer requirements; $k_{i}$ is a relative quality indicator of the $i$-indicator of consumer requirements.

The assessment of identification indicators and safety indicators seeks to establish technological compliance ( $\boldsymbol{a}$ and $\boldsymbol{b}=1$ ) or non-compliance ( $\boldsymbol{a}$ and/or $\boldsymbol{b}=0$, and therefore $\boldsymbol{K}=0$, i.e. at any values of consumer quality indicators, the product quality $=0$, i.e. products cannot be used purposefully and should not be allowed to the market). indicator:

In particular, the qualimetric assessment of curd products uses the following formula of the comprehensive quality

$$
K=15,3 \cdot k_{1}+5,6 \cdot k_{2}+9,5 \cdot k_{3}+3,0 \cdot k_{4}+12,7 \cdot k_{5}+10,3 \cdot k_{6}+9,3 \cdot k_{7}+13,4 \cdot k_{8}+9,1 \cdot k_{9}+4,3 \cdot k_{10}+7,5 \cdot k_{11}, \%,
$$

Where $k_{1 . .} k_{l 1}$ is a relative indicator of such properties of a curd product as: 1 - favorable flavor, 2 - favorable smell, 3 integrity, 4 - even color, 5 - no oozing, 6 - tangible chips/bites, 7 - long shelf life, 8 - healthy ingredients, 9 - no preservatives, added flavors and colors, 10 - low calorific value, 11 - affordable price.

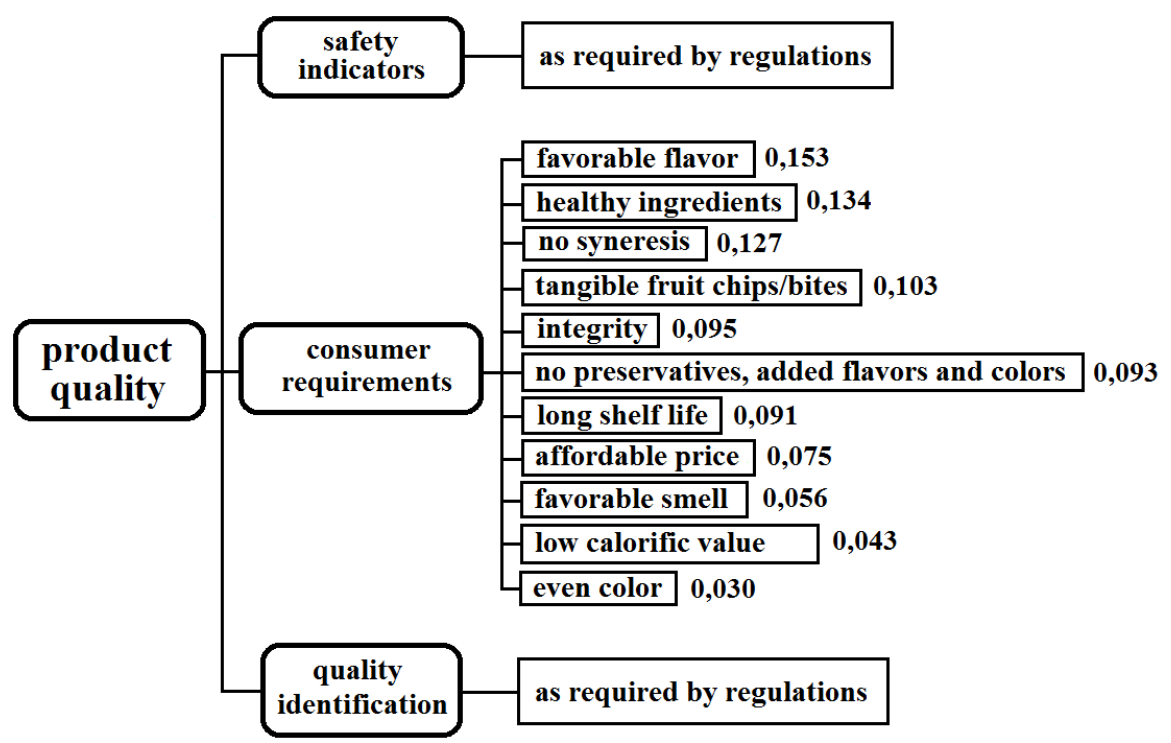

Figure 2. Property tree (consumer requirements branch) with value factors

The results show the main ways to improve curd products: reducing the calorific value, improving healthy properties, increasing the shelf life, no preservatives, eliminating the possibility of syneresis, achieving lasting integrity within storage-life. To pursue desired characteristics in the developed curd product, we chose a food additive containing animal-based dietary fibers (SCANPRO T 95, SCANPRO BR 95 and Tipro 601) that have a number of desirable technological properties (Dunchenko et al, 2004, 2005). 
The full factorial experiment completes the mathematical description of what influence the main components of recipes and technological processes have on the developing desirable properties of the finished product (formulas 3-8):

- for curd body with $10 \%$ fat cream:

for SCANPRO T 95: $Y=45,108-0,675 \cdot k-121,025 \cdot x-0,394 \cdot t+6,221 \cdot k \cdot t+0,011 \cdot k \cdot x+1,551 \cdot x \cdot t-0,025 \cdot k \cdot x \cdot t$,

for SCANPRO BR 95: $Y=0,451+0,843 \cdot k+23,955 \cdot x+0,329 \cdot t+1,402 \cdot k \cdot x$,

for Tipro $601: Y=-56,825+1,341 \cdot k+96,534 \cdot x+1,156 \cdot t+0,549 \cdot k \cdot x+0,008 \cdot k \cdot t-0,624 \cdot x \cdot t+0,017 \cdot k \cdot x \cdot t$;

- for curd body with $20 \%$ fat cream:

for SCANPRO T 95: $\mathrm{Y}=49,888-0,698 \cdot \mathrm{k}-127,217 \cdot \mathrm{x}-0,489 \cdot \mathrm{t}+6,462 \cdot \mathrm{k} \cdot \mathrm{t}+0,012 \cdot \mathrm{k} \cdot \mathrm{x}+2,793 \cdot \mathrm{x} \cdot \mathrm{t}-0,033 \cdot k \cdot x \cdot t$,

for SCANPRO BR 95: $Y=0,473+0,840 \cdot k+24,824 \cdot x+0,293 \cdot t+1,616 \cdot k \cdot x$,

for Tipro 601: $Y=-53,380+1,360 \cdot k+93,510 \cdot x+0,843 \cdot t+0,505 \cdot k \cdot x+0,009 \cdot k \cdot t-0,900 \cdot x \cdot t+0,013 \cdot k \cdot x \cdot t$,

where $k$ is the weight ratio of curd cheese in the curd body, \%; $x$ is the weight ratio of the additive in the curd body, $\%$; $t$ is heat treatment temperature, ${ }^{\circ} \mathrm{C}$.

The study identifies major parameters of the technological process and recipes, which helps to predict and manage key properties of the finished product. These are the type and proportion of an additive, cream weight and fat content, heat treatment temperature of the curd mixture.

The findings establish production technology and recipes for new types of curd products. We've developed and approved technical documentation for new products (TU and TI 9222-050-02068640 "Pasteurized cream cheese ", TU and TI 9222-051-02068640 "Pasteurized cheese spread"). The results have been put into production.

We've also examined the change of key quality indicators of finished curd products during storage. Heat treatment, included in the technology, increased product shelf life from 10 up to 30 days with no preservatives added. The core product properties, as expected by the consumer (no syneresis, integrity), are stable throughout storage time.

Using the qualimetric assessment formula (2) and the public poll, we made a customer satisfaction survey about the properties of new types of curd products developed using qualimetric forecasting in marketing, design, and production (Figure 3).

It establishes that new types of curd products meet consumer requirements to a greater extent and are more preferable for them. This makes this product competitive and proves the effectiveness of adopting qualimetric forecasting in quality management, in particular, in market research, design, production and storage of products.
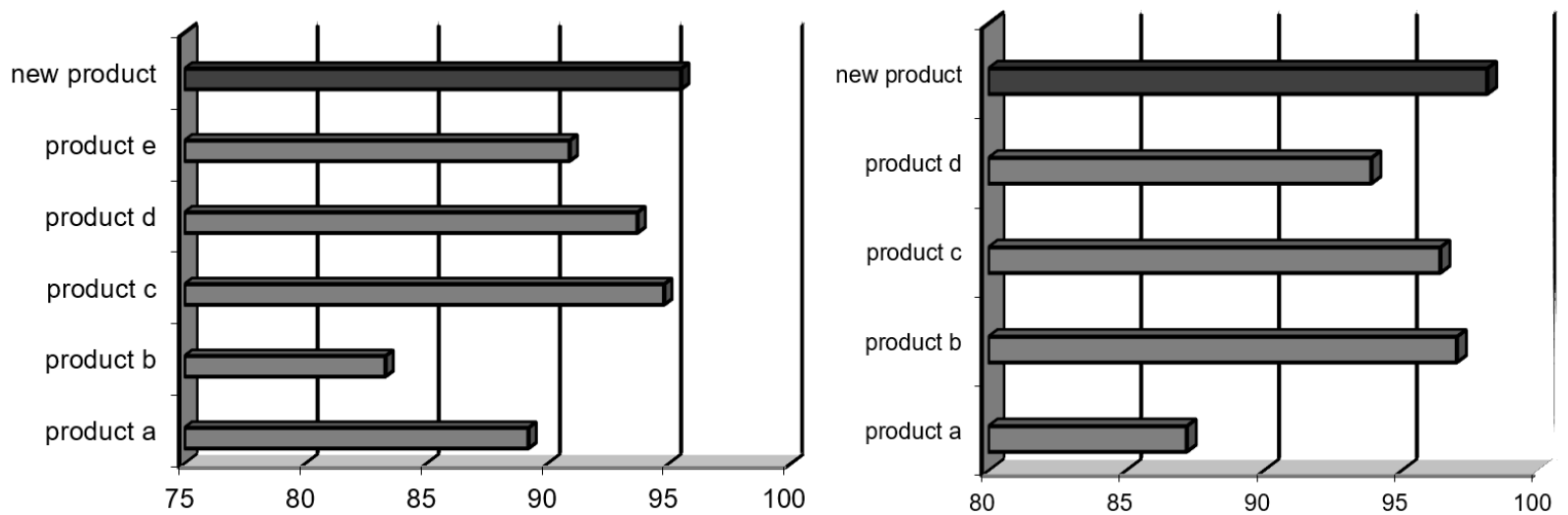

Figure 3. Compared comprehensive quality values of curd desserts (left) and curd cheeses (right) and popular marketed curd products

\section{CONCLUSIONS AND DISCUSSION}

The research substantiates the scientific and practical potential of using universal qualimetry models in management. It discovers ways to effectively apply qualimetry methods in the life cycle of food products It suggests steps for qualimetric product quality forecasting include quality and safety article identification, construction of a property tree and calculation of value factors for quality indicators, complex quantitative assessment methods, identification of numerical values for quality indicators that a food product should have to meet consumer expectations, development of techniques to forecast and control properties of the finished product. The proposed steps have been tested on curd products as an example. We have developed a mechanism for forecasting and managing the main product properties (through 
changes in the type and proportion of an additive, cream weight and fat content, heat treatment temperature of the curd mixture). It brings production technology and recipes for new types of curd products. It establishes that the resulting products have a higher rating among consumers and are more preferable to marketed equivalents.

The findings support using qualimetry methods in quality management, especially, using qualimetric forecasting of curd products in market research, design, production and storage of products, as it enables to assess product competitiveness, customer satisfaction with the product and ensures faster product development to meet consumer expectations.

Qualimetric forecasting feasibility and potential, as advocated by the authors, find verification and take firm ground in other scientific studies (Igonina, 2014., Dunchenko et al, 2018).

\section{REFERENCES}

1. Azgaldov G.G., Kostin A.V., Sadovov V.V. 2012. Qualimetry for all, InformZnanie, Moscow.

2. Azgaldov G.G., Kostin A.V. 2012. The establishment of qualimetry: the riddles of recognition or patterns of development? Economic strategies, Vol. 4, pp. 98-101

3. Borzov A.A., Korneyeva V.M., Korneyev S.S. 2018. Probabilistic assessment of innovation quality at the early stages of its life cycle. Quality and life, Vol. 4, pp. 60-61.

4. Cooper R.G., Kleinschmidt E.J. 1995. Benchmarking the firm's critical success factors in new product development. Journal of Products Innovations Management, Vol. 12, pp. 374-391. https://doi.org/10.1111/1540-5885.1250374

5. Dunchenko, N.I., Al-QA'isi R.S., Yankovskaya V.S., Savenkov I.P., Borisenkova B.V. 2004. Dairy-based, collagen-containing preparations. Dairy industry, Vol. 11, pp. 46-47.

6. Dunchenko N.I., Yankovskaya V.S., Al-QA'isi R.S., Savenkov I.P., Permino, S.I. 2005. Functional and technological properties of collagen-containing milk base. Izvestiya VUZ. Food technology, Vol. 4, pp. 34-36.

7. Dunchenko N.I. Yankovskaya,V.S. 2012. Qualimetric Prediction Deployment in Agro-Industrial Complex. Izvestiya of Timiryazev Agricultural Academy, Vol. 5, pp. 9-17.

8. Dunchenko N.I., Yankovskaya V.S. 2016. Qualimetry. Publishing by RGAU - MSHA, Moscow.

9. Dunchenko N.I., Yankovskaya V.S. 2016. Qualimetric evaluation of agricultural products. Product quality control, Vol. 6, pp. 54-57.

10. Dunchenko N.I., Yankovskaya,V.S. 2017. Scientific basis of food quality management. Publishing by RGAU - MSHA, Moscow.

11. Dunchenko,N.I., Voloshina E.S., Gavrilova O.S., Bezrukov E.A. 2018. Prediction of quality characteristics of yogurt. Dairy industry, Vol. 8, pp. 29-30.

12. Igonina I.N. 2014. Qualimetric prediction of the indicators of quality of fish products for baby food: abstract of dissertation. AllRussian research Institute of meat industry named after V. M. Gorbatov, Moscow.

13. Khvastunov R.M., Jagiello O.I., Korneeva V.M., Polikarpov M.P. 2012. Forecasting methods in qualimetry engineering. Saratov: IPR Media, Moscow

14. Khvastunov R.M. Feofanov A.N., Korneeva V.M., Nakhapetyan E.G. 2009. Qualimetry in mechanical engineering, Examination Moscow.

15. Kuschev S.N., Dunchenko N.I., Yankovskaya,V.S. 2009. Indicators of quality and safety of yogurt products. Dairy industry, Vol. 1, pp. 42-43.

16. Mikhailova K.V., Cherstvoy A.A. 2018. Qualimetric forecasting of quality and safety indicators. Competence, Vol. 7 (78), p. 1113.

17. Mizuno S., Akao,Y. 1994. QFD: The Customer-Driven Approach to Quality Planning and Development, Asian Productivity Organization, Tokyo. Japan, available from Quality Resources, One Water Street, White Plains NY.

18. Vasilev G.E., Lyapustin A.G., Yankovskaya V.S. 2011. The crisis of man in modern civilization. Frontera, Moscow. pp. 69--38.

19. Yankovskaya V.S. 2007. The design of cheese products for the power of youth. Dairy industry, Vol. 12, pp. 71-72.

20. Yankovskaya V.S. 2008. Development of qualimetric model of prediction of indicators of quality and safety of curd products: abstract of dissertation. Publishing by «Polisuvenir», Moscow.

21. Yankovskaya V.S. 2008. Development of qualimetric model of prediction of indicators of quality and safety of curd products: dissertation, Moscow.

22. Yankovskaya V.S., Cherstvoy A.A. 2012. Qualimetric assessment of agricultural products. Technology and merchandising of innovative products, Vol. 5, pp. 80-84. 